\title{
2006-2265: ENGINEERING EDUCATION OF MINORITIES: AN OVERVIEW
}

\section{Eric Asa, North Dakota State University}

ERIC ASA is an Assistant Professor in the Department of Construction Management and Engineering at North Dakota State University, Fargo, North Dakota. He holds a doctoral degree in Civil and Environmental Engineering from the University of Alberta. His research interests include minority science, engineering and technology education; construction materials and processes; computational modeling, simulation and optimization of complex engineering systems/processes (discrete, dynamic and intelligent); equipment selection and maintenance; etc. 


\title{
Engineering Education of Minorities: An Overview
}

\begin{abstract}
The population of the United States is becoming increasingly ethnically diverse. The growing number of minorities in the United States population presents both challenges and opportunities to institutions of higher education across the federation. Minorities (Blacks, Hispanics, American and Indians/Alaskan Natives) are projected to constitute $52 \%$ of the college-age (18-24 years) population of the United States by year 2050; up from 34\% in 1999. Even though the proportion of minorities in the population of the United States is increasing, they have not been as successful in obtaining engineering degrees and diplomas. This is especially true for African Americans and Hispanics who constitute a significant proportion of the US population. Whites constituted about $76 \%$ of undergraduate engineering students in 1990 and $68 \%$ in 2002 . The enrollment of blacks in undergraduate engineering programs actually decreased from $7.0 \%$ in 1995 to $6.3 \%$ in 2002 . Various innovative approaches have been employed by colleges, schools, government establishments, National Science Foundation and minority interest groups to attract minorities to engineering programs. However the retention rate of minorities in engineering programs is about on-third, compared to two-thirds for non-minority groups. Some educators have argued that teaching methods used by engineering programs should even be adapted to suit the learning styles of minorities. Yet others argue that the abysmal number of minorities in engineering programs has more to do with the culture and/or climate in an engineering classroom than intellectual ability. The question still remains as to how best we could attract, retain and educate minorities in engineering.
\end{abstract}

This work is therefore aimed at analyzing the history of minority engineering education, discussing issues surrounding engineering education of minorities and devising a strategy to attract and retain minorities in the engineering disciplines.

\section{Introduction}

In the words of Jim Owens, diversity is an imperative part of business:

"Our future depends on unleashing the potential of all our employees, everywhere. And committed leadership is the key to doing that. One of the things our leaders are doing as we work together to continue building our people culture is focusing on diversity. They're doing this because it is the right thing to do and because diverse backgrounds, experiences, and points of view are good for business.",

The rate of growth of employment opportunities in engineering and science-related fields is fourfold compared with other disciplines. The industry advisory committee purports that the number of jobs in engineering and scientific fields will amount to 2 million by the end of the decade. The growing number of minorities in the United States population presents both challenges and opportunities to institutions of higher education across the federation. This is especially true in engineering education, where the vast majority of students are white and Asian males. The interesting aspect of this phenomenon is that the proportion of white students in high schools has been declining over the past 30 years. This makes the problem even more aggravating and threatening to the integrity of the engineering profession in the United States. 
Efforts to attract minorities in engineering and science disciplines have had very little success. This is especially true in engineering where minorities have not been able to keep up with their ethnic counterparts. It has therefore become necessary that serious attention is paid to minority involvement in higher education.

\section{Methodology}

Over the years various researchers have employed different approaches to analyzing and understanding minority involvement in engineering education. These analyses have led to various actions, which have become the standard practice in minority engineering education. In this research, a number of approaches will be adopted in order to understand minority involvement in higher education which will be followed by suggestions to address the issues. There will be quantitative analyses of available data. This will be followed by analysis of minority involvement in engineering education. The effects of organizations like Accreditation Board for Engineering and Technology (ABET) and National Science Foundation (NSF) will also be considered. Some suggestions aimed at addressing minority involvement in higher education will then be made.

\section{Quantitative Analyses}

A great deal of statistical and population data have been complied over the years and the purpose of this section is to analyze the available data to verify trends and other salient features. Most of the data employed in this section was compiled by NSF. Minorities (Asians/Pacific Islanders, Blacks, Hispanics, and American Indians/Alaskan Natives) are projected to constitute $52 \%$ of the college-age (18-24 years) population of the United States by year 2050; up from $34 \%$ in 1999 . In 1999 , college-age whites (18-24 years) constituted about $66 \%$. This figure will reduce to $48 \%$ in year 2050. Hispanics will experience the highest growth rate within the projected period.

However, whites constituted about $76 \%$ of undergraduate engineering students in 1990 and $68 \%$ in 2002. Undergraduate engineering education of Asians/pacific islanders increased from about $9 \%$ in 1990 to about $12 \%$ in 2002. Undergraduate engineering education of Hispanics increased from about 6\% in 1990 to about 8\% in 2002. Both blacks and American Indians/Alaskan Natives experienced very moderate gains if any. The enrollment of blacks in undergraduate engineering programs actually decreased from $7.0 \%$ in 1995 to $6.3 \%$ in 2002 . The enrollment of white males in engineering programs has held steady at about $81 \%$ over the same period of time. The percentage of white females in engineering has also held steady at about 19\% between 1994 and 2002. Asian males constitute the largest gain in the number of engineering students ${ }^{2}$.

In a study conducted by the Higher Education Research Institute (HERI) in 2002, black freshmen males expressed nearly the same interest $(16.5 \%)$ in engineering as compared to their white male counterparts $(17 \%)^{3}$. Hispanics (17.6\%) and American Indian/Alaskan Natives (15.9\%) males also expressed the same interest in engineering education as the rest of their freshmen counterparts. However, these expressions of interest and possible enrollment in engineering programs did not translate into the same level of retention and graduation rates for all the groups. It has been discovered that generally more than half (53\%) of engineering freshman students transfer into other (non-engineering) programs prior to graduation ${ }^{4}$. 


\section{Minorities in Engineering Education}

The number of women earning doctoral degrees in science and engineering increased from $8 \%$ in 1966 to $37 \%$ in 2001. The number of males earning doctoral degrees dropped in the same period of time. Blacks, especially continue to earn more doctoral degrees in fields other than science and engineering than any other group. In 2001 for instance, blacks earned more than half the doctorates in education and other fields compared to the other groups. Asians/Pacific Islanders earned about $78 \%$ of all the science and engineering doctoral degrees. The dominance of males in engineering doctoral programs is apparent from Figure 1. A disproportionately large number of doctoral degrees have been awarded to males. In 1994, about 6 males received a doctoral degree for every doctoral degree received by a female. Today the proportion is still a high 4:1 in favor of males. Even though there are efforts to close the gap and more females are earning doctoral degrees in engineering than before, the academic gap is extremely wide. Various reasons have been given for this gap, including gender differences. However these reasons alone can not account for such differences. One of the factors that has come to light is the attitude of predominantly male professors towards women and other minorities seeking doctoral degrees in engineering. A number of opinions exist on this matter but the fact still remains that somehow minorities have been crowded out of doctoral degrees in engineering.

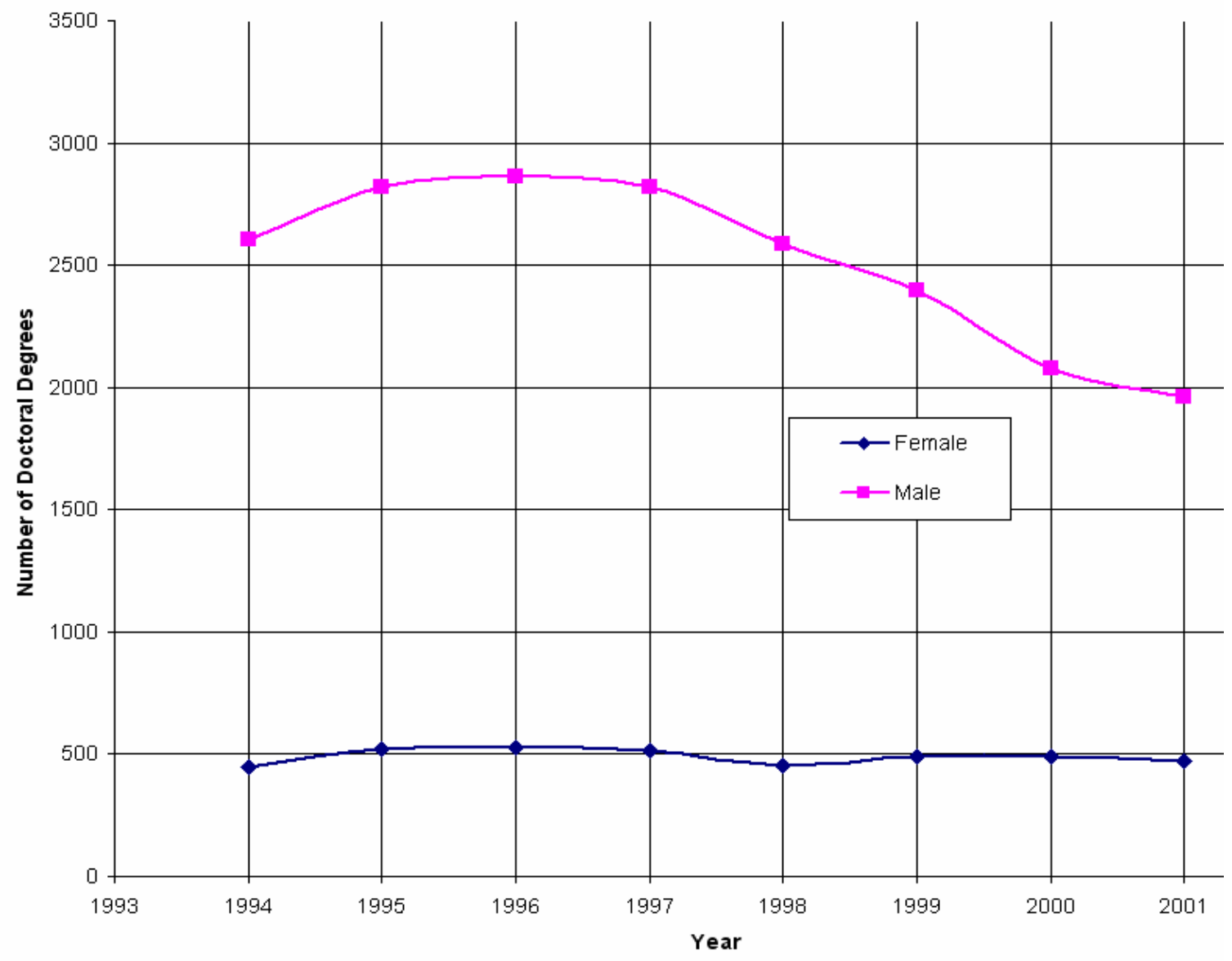

Figure 1: Doctoral Degrees in Engineering Awarded to Males and Females 5 . 
Females and other minorities were awarded more degrees in science than in engineering. For instance females were awarded 6,046 doctoral degrees in sciences as compared to 9,088 males in 1994 (leading to a ratio of about 1.5:1 in favor of males). The ratio reduced to 1.2 males to every female in 2001. Whereas it may take a decade or less for science doctoral degrees awarded to males and females to equalize, it may take 4 or 5 more decades for engineering to catch up. However, this may never happen if attitudes and strategies do not change.

As shown in Figure 2, historically most of the doctoral degrees awarded to engineering graduates were given to whites. In 1994, 2020 doctoral degrees were awarded to whites, 865 to Asian/Pacific Islanders, 54 to Blacks and 66 to Hispanics. In the year 2001, whites received 1746 doctoral degrees. Blacks and Hispanics both received about 91 doctoral degrees in 2001. American Indians/Alaskan Natives were awarded a total of 6 and 7 doctoral degrees in engineering in 1994 and 2001, respectively.

Figure 3 depicts a much clearer view of doctoral engineering degrees awarded between 1994 and 2001.

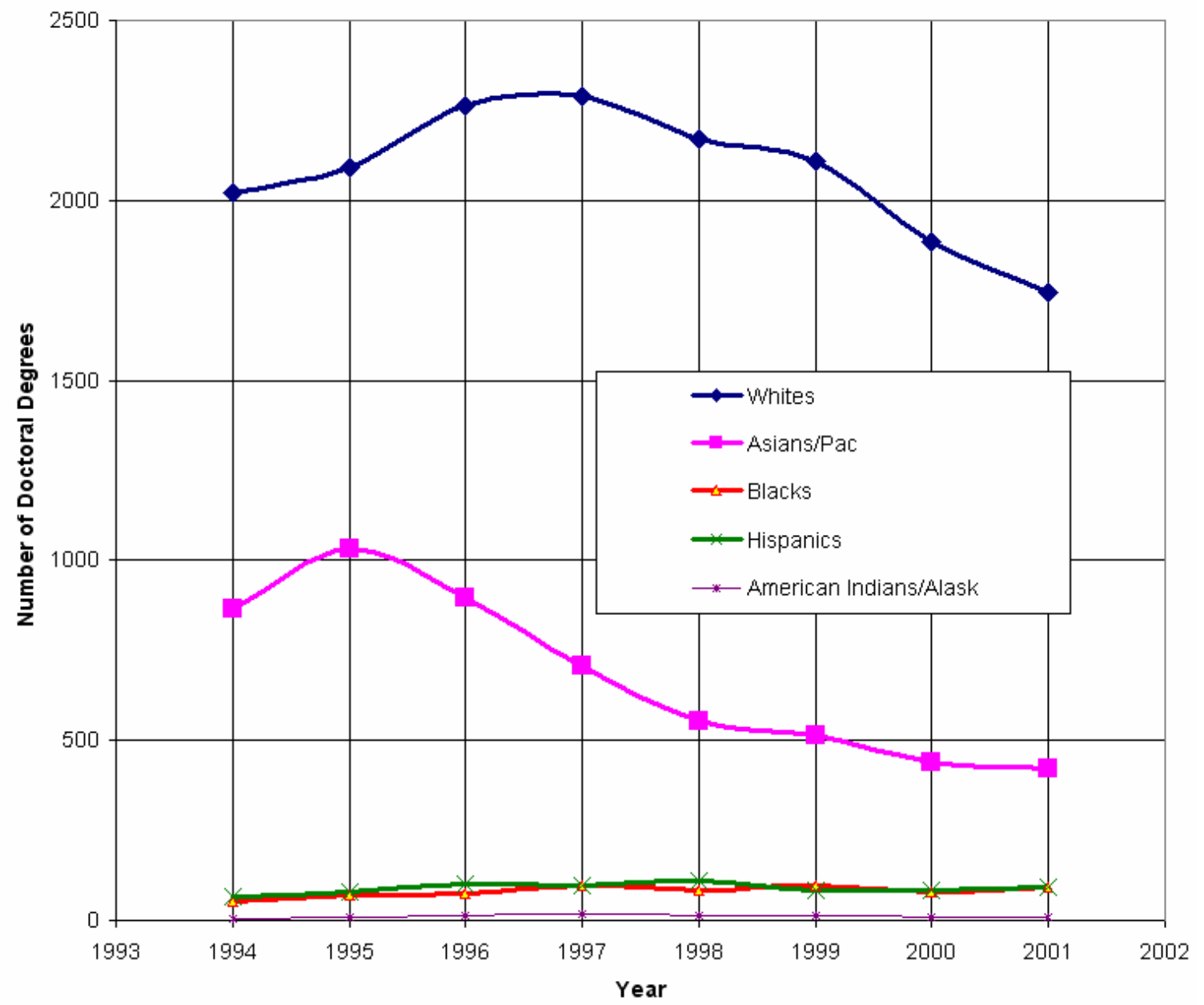

Figure 2: Doctoral Engineering Degrees by Race/Ethnicity ${ }^{5}$. 
A greater proportion of the degrees were awarded to white and Asian/Pacific Islander males. The number of doctoral degrees awarded to these 2 dominant groups have been decreasing since 1996. It is also apparent from the graph that the number of degrees awarded to white females have increased slightly or remained steady between 1994 and 2001. However in the year 2000, about the same number of doctoral degrees were awarded to white females and Asian/Pacific Islander males. The remaining groups, namely black men and women and Hispanic men and women have not seen significant changes in the number of doctoral degrees in engineering. It can therefore be deduced that these later groups of minorities will remain disadvantaged for some time if nothing is done to specifically address the situation. It can also be asserted that the existing system have completely failed these minority groups. They will therefore remain disadvantaged. Some do argue that the number of doctoral degrees in engineering awarded to these groups are increasing. The question still remains as to whether they are increasing fast enough to catch up to their compatriots.

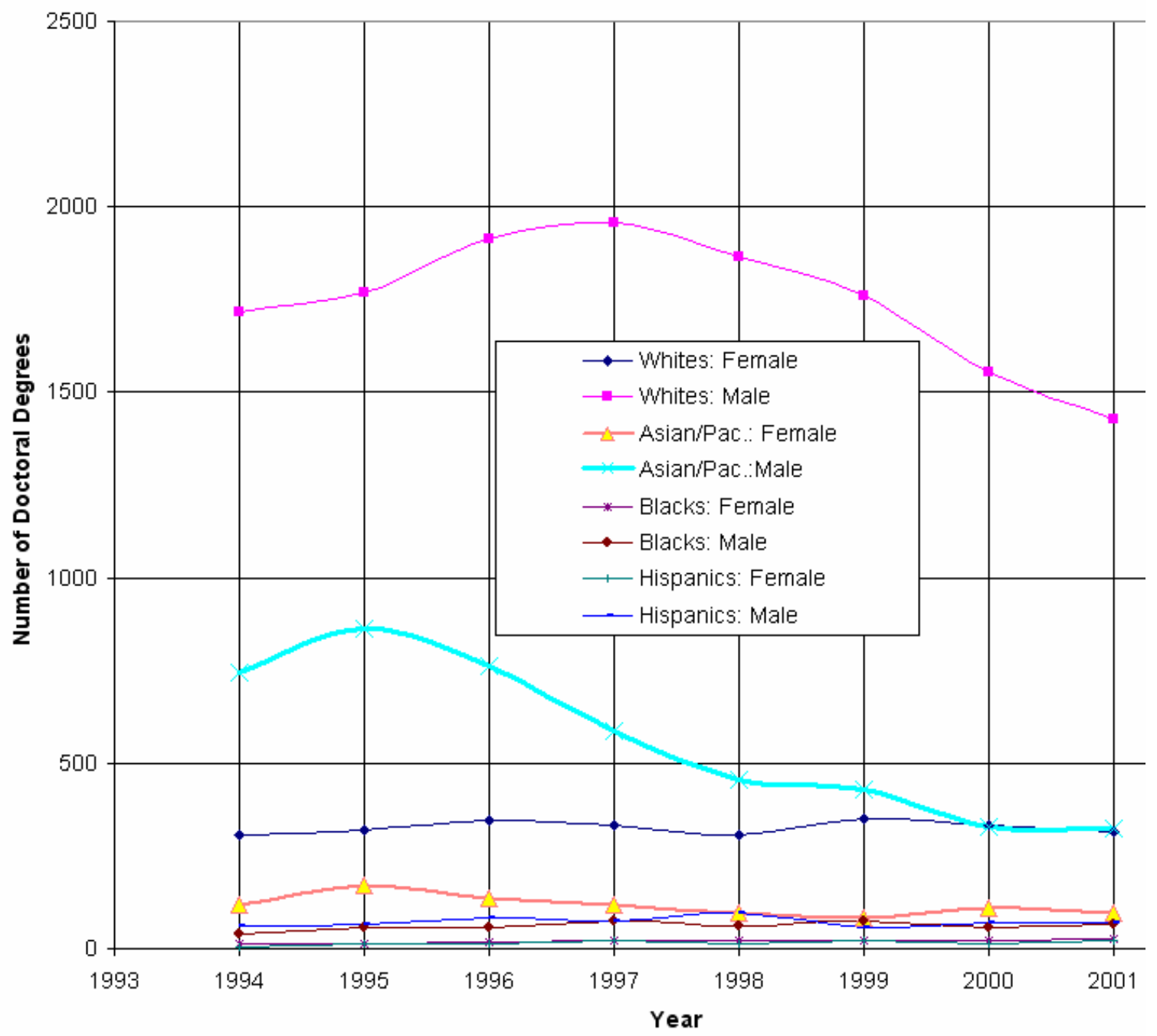

Figure 3: Doctoral Engineering Degrees by Race and Gender ${ }^{5}$. 
The employment status of engineering doctorates in 2001 are shown below in the pie chart (Figure 4).

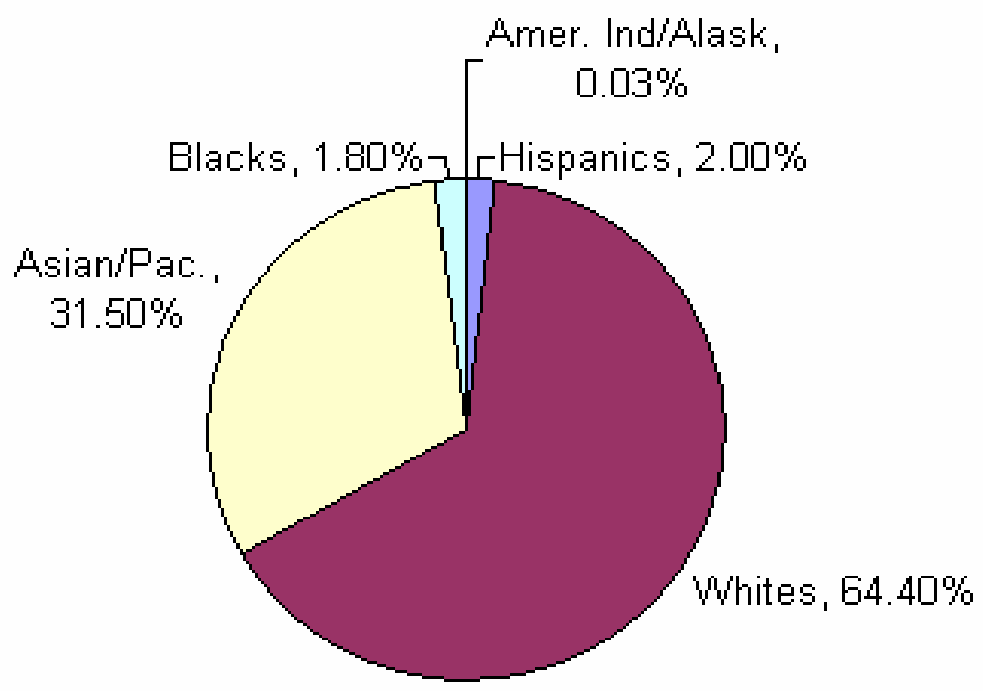

Figure 4: Employment of Engineering Doctorates ${ }^{5}$.

As depicted in Figure 4, in 2001, whites held about $64 \%$ of all the positions, followed by Asians/Pacific Islanders, who held about $32 \%$ of the positions. Hispanics and Blacks held about $2 \%$ for each group.

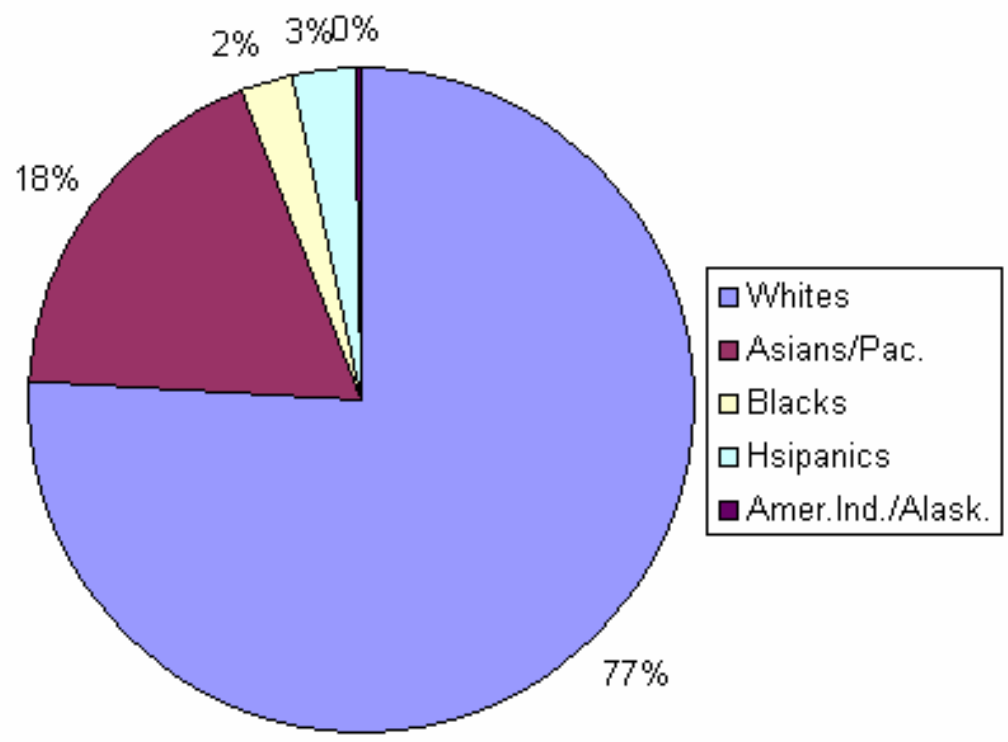

Figure 5: Share of Academic Employment Market in $2001^{5}$.

In 2001 , Whites accounted for about $77 \%$ of academic positions, as compared to $18 \%$ held by Asians/Pacific Islanders, 3\% held by Hispanics and 2\% by Blacks (Figure 5). American Indians and Alaskan Natives held a negligible number of positions in academia in universities and 4-year 
colleges. The attainment of doctoral engineering degrees by minorities is growing so slowly that their membership in academia in future will be very modest if not minimal ${ }^{6}$.

By 2003, about 240 colleges have been designated as Hispanic-serving institutions in the last decade $^{7}$. A greater proportion of the faculty, just like predominantly black colleges, are NonHispanics. This poses a real threat to educating Hispanics. In the words of one of the steering committee members of FACES (Facilitating Academic Careers in Engineering and Sciences, as NSF-sponsored minority program):

"It is very important that minorities pursue academic positions. There are so few minorities in academia, each additional Ph.D. can have a profound impact on the make-up of the college faculty such that it is more representative of society. More importantly, minorities serve as role models for minority students who are considering advanced careers in academia". 8

\section{Strategic Plans of Colleges of Engineering}

Academia is becoming increasingly involved in the strategic planning of their colleges and departments. However a greater proportion of these strategic plans do not explicitly include diversity and/or methods aimed at attracting diverse faculty and students into engineering education. The mission/vision statements of a few higher educational institutions are depicted below.

"We prepare students for professional practice through quality undergraduate and graduate programs that encourage lifelong learning, foster teamwork and leadership, and promote creative discovery. We contribute to the economic well being of..."

"Excellence in innovative, laboratory based technology and engineering programs that is recognized by.............."

The strategic visions of Engineering Colleges of some research universities, which have committed themselves to the involvement of minorities in engineering education are shown below.

“.. Recruit, support and retain.... Increase the number of women faculty members by 15. Add 10 faculty members from under-represented groups..”.

"Faculty Diversity is a special initiative of the Dean of Engineering to recruit and retain a talented and diverse engineering faculty..."

The majority of universities and engineering colleges do not include statements on diversity and/or minority involvement in their vision statements and strategic plans. It can therefore be asserted that these institutions of higher learning have not committed resources to attract and retain minorities in engineering at the same level that they have pursued programs like accreditation and sports. Diversity and minority involvement in engineering education are not just part of their strategic plan and so no resources and actions will be committed to them. More funds are committed to the recruitment of black males as sportsmen than as engineering students. 
Unless some biases are changed, there will remain a vast disincentive for minorities to engage in engineering education as opposed to sports. To most minorities, the opportunity cost of an engineering education is too high as compared to playing in NCAA basketball and/or engaging in activities other than engineering education.

\section{ABET and Support Organizations}

If minorities are to succeed in engineering education, accreditation/professional/funding organizations like ABET, ASCE (American Society of Civil Engineers), SME (Society of Mining Engineers) and NSF must get actively involved, directly and/or indirectly in minority recruitment and retention efforts in higher education.

ABET, the main engineering and technology accreditation organization by it own admission has indicated that the faces of ABET accredited disciplines/programs (applied science, computing, engineering and technology) remain practically unchanged ${ }^{1}$. Minorities for some reason are not making it in ABET accredited programs. Even though ABET has revamped its own structures to include and actively involve minorities in the accreditation process, they have to go a little further. In view of the power and respect bestowed in ABET by Engineering Colleges, ABET must include diversity as part of the core requirements for accreditation.

NSF does require diversity as one of the broader impacts of NSF-sponsored research. It has also directly sponsored some research in minority issues in higher education. However the nature of the problem requires the commitment of more resources as well as active participation in diversity and/or minority programs. NSF should be encouraged to actively pursue minority involvement in engineering education at all levels, since it has the mandate and economic power to effect change.

\section{Strategies to Improve Minority Involvement in Engineering Education}

No one could have described the crisis of our times better than President Shirley Ann Jackson of RPI when she said:

"There is a quiet crisis building in the United States... The crisis stems from the gap between the nation's growing need for scientists, engineers, and other technically skilled workers, and its production of them.... We ignore this gap at our peril. Closing it will require a national commitment to develop more of the talent of all our citizens, especially the underrepresented majority...". 9

The following actions may address the absence of minorities in engineering education:

1. Inclusion of diversity in ABET accreditation criteria

2. Special funds from NSF to recruit minority faculty to mentor minority students

3. Increased sponsorship from corporations

4. Integration of minorities into the vision, structure and politics/policies of engineering colleges

5. Involvement of Regents and Boards of Education in minority issues in universities and colleges 
6. Development of special programs akin to "No Child Left Behind" to attract minorities into and equip them for engineering education

7. Development of minority networks in engineering professional organization.

\section{Conclusion}

The population of minorities in the United States, especially Hispanics, is increasing at a faster rate than other groups. However graduating engineers and engineering faculty continue to be predominantly white and male. This work has shown that minorities are earning far less degrees in engineering than all other fields. Besides white females who have made some headway, minorities with doctoral degrees in engineering are abysmally low. Minorities earn far more doctoral degrees in the sciences than in engineering. Efforts to attract minorities into engineering have not been successful. This may be due to the fact that engineering faculty is mostly white and predominantly male. White (77\%) and Asian/Pacific Islander (18\%) males together held a disproportionately high number of faculty positions in 2001. The strategic plans/visions as well as actions of universities (and engineering colleges) have resulted in attracting minorities into sports (especially black men) rather than engineering. The actions of other organizations like ABET and NSF have directly or indirectly aggravated the problem. It is therefore imperative that minority involvement in engineering education be pursued with some aggression. Some of the proposed actions are inclusion of diversity in ABET accreditation criteria, the creation of special funds by NSF to fund minority faculty and the creation of special programs to attract minorities into engineering education. There is a quiet but serious crisis (shortage of engineers and exclusion of minorities) brewing in the engineering profession and action must be taken to address it, else it is getting out of hand.

\section{Bibliography}

1. ABET, 2004. "Issues of Accreditation in Higher Education. Volume III: Diversity".

2. Engineering Workforce Commission, American Association of Societies, 2003.

3. Higher Education Research Institute (HERI), University of California, Los Angeles, 2002.

4. Shuman, L.J., Delaney, C., Wolfe, H., Scalise, A., and Besterfield-Sacre, M., 1999. "Engineering Attrition: Student Characteristics and Educational Initiatives", ASEE Education Conference, Charlotte, NC, 1999.

5. National Science Foundation, 2004, "Women, Minorities, and Persons with Disabilities in Science and Engineering".

6. Babco, Eleanor L., 2001, “Under-represented Minorities in Engineering: A Progress Report”. Commission on Professionals in Science and Technology, July 2001.

7. Schmidt, Peter, 2003, "A special Report: Academe's Hispanic Future” The Chronicle of Higher Education. November 28, 2003.

8. DesRoches, Reginald, 1999 "Minority Students Pursue Academic Careers in Engineering”, Press Release, Georgia Institute of Technology, Atlanta, Georgia, May 26, 1999.

9. Jackson, Shirley Ann, 2001 "The Quiet Crisis: Falling Short in Producing American Scientific and Technical Talent, September 2001. 


\section{BIOGRAPHICAL INFORMATION}

ERIC ASA is an Assistant Professor in the Department of Construction Management and Engineering at North Dakota State University, Fargo, North Dakota. He holds a doctoral degree in Civil and Environmental Engineering from the University of Alberta. His research interests include minority science, engineering and technology education; construction materials and processes; computational modeling, simulation and optimization of complex engineering systems /processes (discrete, dynamic and intelligent); and equipment selection and maintenance.. 